\title{
Estados incomuns de consciência em parturientes: a partolândia enquanto potencial para desenvolvimento da mulher
}

\section{Unusual states of consciousness in parturients: partolândia as a potential for the development of woman}

Estados inusuales de conciencia en mujeres parturientas:
partolandia como potencial para el desarrollo de la mujer

Leonardo Xavier de Lima e Silva*

Universidade Federal de Pernambuco - UFPE, Recife, Pernambuco, Brasil

\author{
Aurino Lima Ferreira** \\ Universidade Federal de Pernambuco - UFPE, Recife, Pernambuco, Brasil
}

Luiziane Souza Vasconcelos de Lima***

Universidade Federal de Pernambuco - UFPE, Recife, Pernambuco, Brasil

\begin{abstract}
RESUMO
A assistência ao parto passou por importantes transformações nos últimos séculos. Neste processo, o modelo tecnocrático tornou-se hegemônico, promovendo uma atitude passiva nas mulheres. Evidências mostram, entretanto, que em trabalho de parto a mulher é tomada por estados incomuns de consciência, conhecidos como partolândia, que a tornam ativamente apta ao efetivo trabalho de parto, e a uma experiência de vida positivamente marcante. Objetivou-se discutir como a emergência desses estados potencializa melhores desfechos de parto e promove o crescimento pessoal da mulher. Assim, realizou-se reflexão teórica baseada no modelo integral de Wilber, na teoria do território de nascimento de Fahy, levando em conta os modos contemporâneos de assistência ao parto (Davies-Floyd), e uma visão arquetípica de transformação feminina (Nogueira). A partolândia apresenta-se enquanto modificação na percepção de espaço e tempo, emocionalidade e intuição aguçadas, insights psíquicos, revivescência de traumas etc. Conhecer os estados de consciência da mulher no parto, e os meandros do território de nascimento no qual emergem, pode auxiliar na assistência à parturição, além de viabilizar transformações que impliquem em desenvolvimento psicológico para a mulher.
\end{abstract}

Palavras-chave: consciência, parto, desenvolvimento, empoderamento, espiritualidade.

\footnotetext{
ABSTRACT

Childbirth care has undergone major transformations in recent centuries. In this process, the technocratic model became hegemonic, promoting a passive attitude in women. Evidence shows, however, that in labor the
} 
woman is taken by unusual states of consciousness, known as partolândia, which makes her actively fit for effective labor and a positively marked life experience. The objective was to discuss how the emergence of these states enhances better delivery outcomes and promotes women's personal growth. Thus, theoretical reflection based on Wilber's integral model, Fahy's birth territory theory, taking into account contemporary modes of childbirth care (Davies-Floyd), and an archetypal vision of female transformation (Nogueira). Partolândia presents itself as a modification in the perception of space and time, sharpened emotionality and intuition, psychic insights, revives of traumas etc. Knowing the states of consciousness of the woman in childbirth, and the meanders of the territory of birth in which they emerge, can help in the parturition assistance, besides making viable transformations that imply in psychological development for the woman.

Keywords: consciousness, childbirth, development, empowerment, spirituality.

\section{RESUMEN}

La asistencia al parto ha pasado por importantes cambios en los últimos siglos. En este proceso, el modelo tecnocrático se volvió hegemónico, promoviendo una actitud pasiva en las mujeres. Las evidencias muestran, sin embargo, que en trabajo de parto la mujer es tomada por estados inusuales de conciencia, conocidos como partolandia, que la hace activamente apta al efectivo trabajo de parto, ya una experiencia de vida positivamente marcante. Se objetivó discutir cómo la emergencia de esos estados potencializa mejores resultados de parto y promueve el crecimiento personal de la mujer. Así, se realizó una reflexión teórica basada en el modelo integral de Wilber, en la teoría del territorio de nacimiento de Fahy, teniendo en cuenta los modos contemporáneos de asistencia al parto (Davies-Floyd), y una visión arquetípica de transformación femenina (Nogueira). La partolandia se presenta como modificación en la percepción de espacio y tiempo, emocionalidad e intuición agudas, insights psíquicos, revivescencia de traumas, etc. Conocer los estados de conciencia mujer en el parto, y las complejidades del territorio de nacimiento en el que emergen, pueden ayudar en la asistencia al parto, así como proporcionar las transformaciones que resultan en el desarrollo psicológico para las mujeres.

Palabras clave: conciencia, parto, desarrollo, empoderamiento, espiritualidad.

\section{Introdução}

Ao longo de milênios, o parto e nascimento foram considerados eventos com forte caráter numinoso e ritual (Lahood, 2007). Registros milenares apontam a sacralidade do momento, os inúmeros rituais ligados ao mistério da vida e da maternidade. Além disso, a ligação com o arquétipo da Grande Mãe, com a terra e seus frutos, com a vida em seu aspecto mais abrangente, parece ser um dos mais antigos registros do inconsciente coletivo (Jung, 2000; Neumann, 1999; Woolger \& Woolger, 2000). O evidente aspecto feminino presente na experiência de gestação, parto e maternidade, tornava as mulheres as pessoas mais adequadas a apoiarem umas às outras durante a transição vivenciada no parto/nascimento. E assim 
surgiram as parteiras ao longo da história, cuja exata origem se perde na noite dos tempos.

A partir das várias transformações socioculturais que ensejaram o nascimento da ciência moderna, iniciou-se paulatinamente uma contenda entre as mulheres parteiras tradicionais e os recémsurgidos homens de ciência. O auge teria se dado por volta do século XVIII, com o nascimento oficial da obstetrícia, em que a arte de partejar, pautada na tradição e na experiência da parteira, foi oficialmente convertida em categoria da cirurgia - ou seja, em ciência do parto. A eloquência dos médicos na desqualificação das parteiras ajudou os cirurgiões-parteiros na legitimação da profissão, rompendo a longa preponderância da autoridade das comadres no que se refere ao ato do nascimento (Barreto, 2007).

Somente na segunda metade do Século $X X$, particularmente com os movimentos feministas, houve uma reação forte o bastante para questionar, dentre outras, as bases ideológicas da ciência obstétrica. O que se discutia não era tanto a tecnologia médica que vinha trazendo importantes contribuições para a assistência ao parto, a exemplo da cirurgia cesariana, responsável por salvar inúmeras vidas. O que estava em questão era o autoritarismo masculino conjugado ao crescente abuso de tecnologias e intervenções, praticadas até a atualidade, e que contrariam recomendações de instituições como a Organização Mundial de Saúde (OMS/1996).

Em razão desta virada histórica na assistência ao parto, a partir da hegemonia do modelo racional, técnico e higiênico, o ambiente paradigmático de ocorrência dos nascimentos humanos tornou-se o centro hospitalar, cujas marcas principais são a assepsia, o isolamento, a tecnologia e o controle de enfermidades. Em sendo essencialmente controlado pelos médicos e pela instituição hospitalar, o ambiente de nascimento perdeu a característica de intimidade, aconchego e participação familiar que apresentava outrora. Nesse sentido, passou a inibir os processos fisiológicos da parturição, em razão de não oferecer as necessárias condições para o acolhimento da mulher. Por consequência, os estados de consciência favoráveis ao processo de parto, relacionados a certas condições neuro-hormonais, deixaram de ser estimulados. Em decorrência da intrusão ambiental das novas tecnologias, os organismos femininos passaram a apresentar, bem mais frequentemente, reações defensivas, mediante, por exemplo, a secreção de adrenalina, hormônio relacionado ao medo e que inibe as contrações uterinas. O medo e outras emoções, relacionadas ao estresse, ao estado de alerta, contribuíram para compor o ideário social de que o parto normal seria algo perigoso, inseguro, e extremamente doloroso, além de reforçar uma suposta incompetência do corpo feminino para realizar adequadamente 0 processo parturitivo. 
Neste contexto, Carneiro (2013) vai falar das mulheres que ousam romper com a ideia do parto sofrido, desafiando o modelo hegemônico, desenvolvendo novas percepções sobre as dores do parto. Vai definir, assim, a partolândia como um estado alterado de consciência, um flash, instante ou poucos minutos em que se perderia a razão, figurando, por isso, um "vazio no qual não se pensa, somente se sente; uma percepção de que se está em outro lugar, sem saber quem está por perto, uma zona de pensamento em branco" (Carneiro, 2013, p. 2374). A autora baseia-se no entendimento do pioneiro obstetra francês Michel Odent $(2000,2008)$ quando asseverou que, mediante os hormônios do amor - serotonina e ocitocina - a mulher estaria envolta numa atmosfera psíquica pouco afeita à moral civilizada, podendo apresentar diversas expressões como: gritos, gemidos, choros, gargalhadas etc. Apesar de partir dessas explicações, para Carneiro (2013, p. 2375) a perspectiva de Odent nos remete às teorias científicas, enquanto a visão feminina "nos conduz à 'partolândia' e, por consequência, às interfaces entre parto, espiritualidade e sexualidade". Nesta direção, dada a proximidade com a experiência sexual, este estado de consciência apresenta um forte caráter de erotismo, transformando a experiência de parto em situação complexa que conjuga dor e prazer. Algumas mulheres chegariam a ter orgasmos na hora de dar à luz, como sugere o documentário de Debra-Pascali (2009): Orgasmic Birth.

$\mathrm{Na}$ atualidade, estando o parto imerso em uma cultura hegemonicamente masculina, a qual retira das mulheres o poder sobre o próprio corpo e, consequentemente, sobre o processo da parturição (Davies-Floyd, 2001), vê-se a passividade com que muitas se colocam perante os assistentes do pré-natal e parto, tornando-as manipuláveis, e à mercê do sistema tecnocrático de saúde. Em contrapartida, quando nasce o impulso de transformação, "o perfil de mulher que emerge é aquele de alguém que, levando adiante as conquistas de seus direitos civis, trata agora de emancipar-se de correntes interiores que a prendem à falta de confiança em si mesma, em seu corpo, intuição e poder pessoais" (Nogueira, 2013b, p. 18). Nesta linha, Karadi (2014) assevera que, durante o período gravídicopuerperal, o mundo emocional da mulher caracteriza-se por uma incomum abertura psicológica. À medida que o controle consciente do ego vai perdendo força, dimensões mais profundas vão atravessando as defesas, levando a um estado regressivo natural, em que a mulher é chamada a olhar dentro de si mesma, enquanto nela cresce um forte senso intuitivo.

Em outra vertente, pesquisadores encontraram evidências empíricas de estados incomuns de consciência específicos de gênero, a partir de medidas psicométricas e eletroencefalográficas de mulheres, tanto antes quanto após o parto (Spivak, Bechtereva, Spivak, Danko, \& Wistrand, 1998; Gruzdev \& Spivak, 2006). Para eles, a importância 
destes estudos estaria relacionada à verificação de como estes estados se manifestam na situação estressora do parto, até mesmo como um dispositivo de coping. Além destes, outro clássico investigador na pesquisa da consciência, Stanislav Grof (1985, 1998, 2000), trouxe amplas contribuições sobre o potencial terapêutico destes estados, porém no que tange ao parto vê-se uma grande ênfase no trauma do nascimento e na possibilidade de emergências espirituais dele decorrentes. Face a isto, Lahood (2007) faz a crítica de como um evento eminentemente espiritual como este tem sido pouco abordado pelos pesquisadores orientados pela visão transpessoal, sugerindo que o domínio médico do território de nascimento pode ser uma das razões desta lacuna, dentre outras de natureza socioantropológica.

Desta forma, reconhecido o interesse científico e sociocultural dos estados incomuns de consciência no parto, para a experiência existencial da mulher, pretende-se discutir, à luz de uma visão integral, o papel desses estados (partolândia), descrevendo sua dinâmica em função do ambiente, sua influência perante os desfechos de parto, e algumas repercussões para o desenvolvimento da mulher.

\section{Referencial Teórico}

Um primeiro norteador teórico para tematizar a chamada partolândia será o modelo integral de Wilber (2000, 2006, 2011). Para caracterizar a experiência psicológica da mulher no parto, especialmente as repercussões em seu desenvolvimento, será utilizada a abordagem arquetípica de Nogueira (2013a, 2013b). Além destas visões, também se fará referência à teoria do território de nascimento de Fahy et al. (2011), e a alguns aspectos da caracterização dos modelos assistenciais de parto, feita por DaviesFloyd (2001).

Wilber (2006) propõe que todo evento emerge e pode ser visto a partir de quatro dimensões representadas em quatro quadrantes: intencional, cultural, comportamental e social. O olhar intencional é a visão fenomenológica, o como se apreende intuitiva e interiormente um objeto de percepção. O cultural é a dimensão interior do coletivo, as visões de mundo, sistemas culturais e linguísticos, que compõem determinado fenômeno. Comportamental é a visão dos sinais corporais, físicos, observáveis, de um evento ou fenômeno individual. Finalmente pelo prisma do quadrante social é possível estudar os sistemas, as instituições e estruturas físicas do coletivo, as condições e construções sociais materiais sobre as quais se apoiam as culturas, e suas visões de mundo.

Em se tratando de estados de consciência, Wilber (2006) parte de um ponto de vista relativamente simples. Todos os seres humanos 
dormem, sonham e acordam, e assim vivenciam cotidianamente estados diferenciados de consciência, com suas experiências próprias. Segundo o autor, há vários mapas da consciência que procuram dar conta desta fenomenologia, porém a maioria não intercambia seu conhecimento com aquele trazido pelo estudo das estruturas de consciência, que são "padrões holísticos dinâmicos" (Wilber, 2006, p. 98), os quais caracterizariam, segundo o autor, os níveis de consciência estudados por teorias estruturalistas e desenvolvimentistas. Assim, integrando ambos os aspectos fenomenológico e estrutural, Ken Wilber juntamente com Allan Combs vão conceber a chamada grade Wilber-Combs, segundo a qual cada experiência de estado de consciência é sempre interpretada segundo o nível ou estágio de desenvolvimento da pessoa que o vivencia.

Por exemplo, durante uma experiência de parto, uma parturiente poderia vislumbrar uma luz que é por ela interpretada como a luz do Espírito Santo, e por outra como uma distorção perceptual causada por ativações neuronais. Ou seja, conforme a maneira de se estruturar aquela experiência, necessariamente construída através de um sistema simbólico-cultural, e o nível de organização estrutural da consciência, ter-se-á caracterizações distintas de uma mesma experiência fenomenológica. Portanto, há de se levar em conta esta dimensão no estudo dos estados de consciência da mulher no parto, aspecto este, entretanto, que não será aqui aprofundado por limitação de espaço.

Fundamentada em uma perspectiva arquetípica, Nogueira (2013a) vai teorizar sobre o que chama de alma do parto, ponderando que ela foi perdida ao longo das últimas décadas. Enfatiza que, durante o processo de emancipação e luta das mulheres por um parto mais respeitoso, uma espiritualidade feminina tem emergido; não mais aquela do patriarcado, do Deus que está nos Céus, mas da Deusa incorporada que se manifesta no corpo feminino. Neste sentido, refere que, durante o ciclo gravídico-puerperal, a mulher vai atravessar várias etapas psicológicas que trarão evidentes repercussões para o seu desenvolvimento.

Fahy et al. (2011) vão caracterizar a teoria do território de nascimento, a partir de alguns conceitos-chave. Território aqui é visto tanto como o terreno que inclui características físicas do ambiente, quanto a jurisdição, referente ao uso do poder que é feito dentro desse espaço. Segundo as autoras, uma boa guarda de parteria (midwifery guardianship) seria aquela em que o poder integrativo é garantido. Este é compreendido como o poder que suscita a integração corpo-mente-espírito, tanto da parturiente quanto das demais pessoas presentes no território de nascimento. O poder integrativo seria reflexo do si-mesmo interior (inner self), o qual permitiria a conexão e expressão espontâneas da mulher durante o processo parturitivo. Ao contrário, o poder desintegrativo estaria mais 
relacionado com o ego e sua tentativa de controle da situação, do uso de mecanismos de defesa para lidar com as incertezas inerentes ao parto. Em tudo, o objetivo da guarda de parteria será assegurar o território para que não se torne um ambiente de vigilância e controle; ao contrário, assemelhe-se mais a um santuário, onde possam emergir os potenciais espirituais da mulher que são favoráveis ao processo.

A guarda do parto está muito relacionada com os modelos assistenciais. Davies-Floyd (2001) vai caracterizar três principais modelos: tecnocrático, humanizado e holístico. As principais características do modelo tecnocrático são: separação mente-corpo, corpo como máquina, paciente como objeto, alienação do profissional em relação ao paciente, diagnóstico e tratamento de fora para dentro, organização hierárquica e padronização dos cuidados, a autoridade e a responsabilidade são do profissional, não da paciente, valorização excessiva da ciência e da tecnologia, intervenções agressivas com ênfase em resultados em curto prazo, morte como fracasso, sistema guiado pelo lucro, intolerância para com outras modalidades. O modelo humanizado pressupõe: conexão mentecorpo, corpo como organismo, paciente como sujeito de relação, relação e cuidados entre o profissional e a paciente, diagnose e cura de fora para dentro e de dentro para fora, equilíbrio entre as necessidades do indivíduo e as da instituição, informação, tomada de decisão e responsabilidade repartida entre o profissional e a paciente, ciência e tecnologia contrabalançada pela humanização, enfoque na prevenção, morte como uma possibilidade aceitável, cuidados movidos pela empatia, mentalidade aberta frente a outras modalidades. Já o modelo holístico baseia-se em: unidade corpomente-espírito, corpo como um sistema de energia conectado com outros sistemas de energia, curar a pessoa inteira em seu inteiro contexto de vida, unidade essencial entre o profissional e o cliente, diagnoses e cura de dentro para fora, individualização dos cuidados, autoridade e responsabilidade inerente ao indivíduo, ciência e tecnologia colocadas a serviço dos indivíduos, visão em longo prazo na criação e manutenção da saúde e do bem estar, morte como uma etapa do processo, foco na cura e convivência de múltiplas modalidades de cura.

\section{Metodologia}

Como já citado, a ideia central deste artigo é realizar uma reflexão teórica sobre os estados incomuns de consciência (EiC) que costumam emergir durante o parto fisiológico, sua relação com o território de nascimento, e possíveis repercussões transformadoras para a mulher, baseadas nesta experiência. Para isso, pretende-se 
começar situando o parto nos quadrantes propostos pelo modelo de Wilber (2006). Em seguida, discutem-se aspectos fisiológicos e comportamentais da experiência de parto, relacionando-os ao ambiente onde a mulher está inserida, à luz da teoria do território de nascimento (Fahy et al., 2011), na interseção com os modelos de assistência ao parto (Davies-Floyd, 2001). Logo depois, busca-se discorrer sobre alguns aspectos subjetivos que emergem das experiências de parto, em função da preparação, do ambiente, dos cuidados, enfim, da assistência oferecida, como também algumas ressonâncias dessa experiência, envolvendo os EiC, com o desenvolvimento da mulher (Nogueira, 2013a, 2013b).

\section{Resultados e Discussão}

\subsection{Situando o parto nos quadrantes do Modelo Wilberiano}

Em se tratando de parto e nascimento, iniciando-se pela perspectiva do social, vemos que na atualidade a instituição hospitalar é o lócus paradigmático da assistência. Isto vale, em verdade, para o tratamento da maioria das doenças, sendo gestação e parto ainda concebidos como estados muito próximos de enfermidades. Com base no sistema capitalista, a assistência à saúde ao longo do tempo foi se tornando cada vez mais um "negócio", visando, portanto, o lucro. Com o progresso tecnológico, no caso do parto especificamente, o aperfeiçoamento da cirurgia cesárea, o parto foi se tornando um evento mecânico, produzido em série. O sistema se organizou, portanto, para produzir cada vez mais rapidamente e "higienicamente" o nascimento de novos seres humanos (DaviesFloyd, 2001, 2009).

Ao se olhar por uma lente cultural, perscrutando-se a visão de mundo relacionada aos sistemas sociais, constituídos cada vez mais por ambiências tecnológicas, vemos que há um modelo hegemônico, historicamente construído, que associou fortemente o evento do parto à noção de risco e à ideia de que o corpo feminino é essencialmente defeituoso, ou seja, incapaz de realizar o processo de parturição - não obstante o fato lógico de que, até pouco tempo atrás, comparado à história da espécie humana, todos nasciam de partos naturais, sendo um processo filogenético aperfeiçoado ao longo de milênios.

Em oposição ao modelo tecnocrático, (res)surge em meados do Século $X X$, junto a um ideário de profundo questionamento à técnica, à ciência moderna e seus produtos, uma tentativa de lançar uma visão mais humanizante sobre o parto. Nesta perspectiva, ele é concebido como um evento familiar, íntimo, e que tem a mulher como principal protagonista. Neste sentido, nasceram os movimentos 
sociais pela humanização do nascimento, ao redor do mundo, visando devolver à mulher o poder de escolha sobre seu corpo e seu parto. A partir deste modelo, o domićlio retorna a ser o ambiente paradigmático, o local de maior intimidade e, possivelmente, onde esta mulher se sentirá mais segura e protegida.

Pela perspectiva comportamental (Quadrante SD do modelo de Wilber), vê-se no parto um evento eminentemente fisiológico. Baseando-se em visão tecnocrática, estar-se-á observando meramente os marcadores biológicos: níveis hormonais, sinais e sintomas, comportamentos e expressões físicas observáveis que indiquem determinado estágio do processo de parturição. Assim, a dor torna-se um elemento absolutamente indevido que deve ser debelado a qualquer preço, o que se procura fazer mediante variadas intervenções. Na visão humanizante, os sinais comportamentais sinalizarão as dores de um ser humano, atravessando momento de intensas transformações. Neste sentido, visando proporcionar alívio à mulher, serão oferecidos em princípio métodos não farmacológicos (exercícios físicos, massagens, banhos em água morna), além de se promover o cuidado efetivo, mediante acolhimento afetuoso, preferencialmente com a participação de pessoas significativas a ela.

A Figura 1 representa a visão do parto nos quatro quadrantes, sendo o superior esquerdo 0 Intencional, 0 superior direito 0 Comportamental, o inferior esquerdo o Cultural, e o inferior direito o Social.

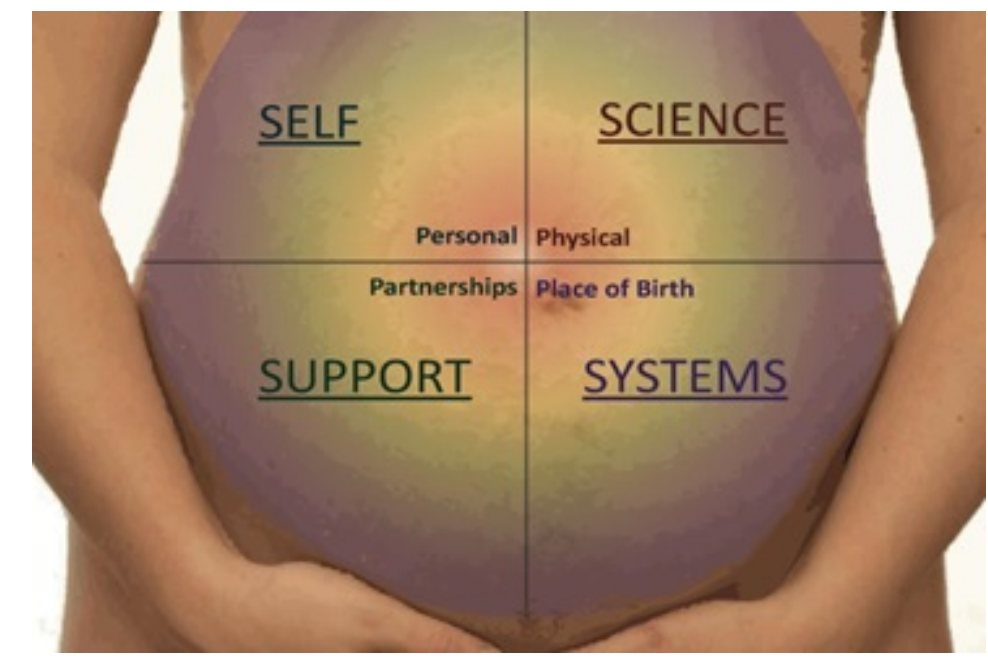

Figura 1. O parto nos quatro quadrantes do modelo integral. Fonte: Radloff (2013).

Observando-se pela visão intencional do SE, percebem-se as repercussões íntimas do evento parturitivo. A partir deste âmbito, observar-se-ão as emoções, os pensamentos, os desejos, os estados de consciência vivenciados e expressos pela própria parturiente. Quando ela se encontra em ambiência onde não se sente segura, 
longe das pessoas que the representam apoio, sofrendo intervenções várias, muitas vezes com vistas a acelerar o processo de parto, a fisiologia de seu corpo irá sinalizar com respostas hormonais típicas de situação de perigo. Os níveis de adrenalina se elevam, dificultando as contrações uterinas e, em decorrência, prejudicando o próprio trabalho de parto. Junto à dor, poderão surgir emoções negativas como medo, raiva, tristeza etc. Em virtude da intensa emocionalidade, esta mulher criará uma vívida lembrança negativa deste evento, ainda que, ao ter contato com o bebê, uma onda de emoções positivas possa surgir. Entretanto, esta sistemática violenta da assistência tem contribuído para os casos de baby blues (Schwengber \& Piccinini, 2004) e depressão pós-parto (Souza, 2014). Ao contrário, quando a mulher é bem acolhida nesse momento, seu corpo estará liberando os chamados hormônios do amor (Odent, 2000), responsáveis tanto pela boa progressão do trabalho de parto, como por sentimentos de prazer. O principal destes hormônios é a ocitocina, que também ajuda a lidar com a dor das contrações uterinas.

\subsection{EiC e alguns hormônios do parto}

Alguns hormônios adquirem particular importância por ocasião do parto. É reconhecido, por exemplo, que a ocitocina natural está ligada ao relaxamento e à sensação de prazer. Durante o trabalho de parto propriamente, provoca contrações uterinas para a saída do bebê, evita hemorragias, além de induzir o comportamento maternal essencial para a relação mãe-bebê (Nephew, 2012). É considerado o hormônio do amor (Odent, 2000).

Já as endorfinas, secretadas durante o trabalho de parto, servem como analgésicos naturais, aliviando as dores além de ajudar a mulher a entrar em estados incomuns de consciência. Logo após o parto, geram um estado de relaxamento, prazer e paixão pelo bebê. Por outro lado, a adrenalina liberada nos estágios finais do trabalho de parto funciona como uma injeção de energia. Se liberada durante - labor parturitivo, ela pode desacelerar ou mesmo interrompê-lo, diminuindo a ação das endorfinas (aumentando a sensação dolorosa) e diminuindo o fluxo sanguíneo para o útero, o que consequentemente diminui a oxigenação do bebê (Fahy \& Hastie, 2008).

Estudando-se os estados de estresse, vivenciados por gestantes e parturientes, chegou-se à ideia da chamada cascata-do-medo, cujo postulado é que quando a mulher está sozinha, desapoiada durante o trabalho de parto, torna-se ansiosa e dominada pelo medo. Em tal estado emocional, o sistema nervoso autônomo pode assumir o controle de muitas funções fisiológicas, como por exemplo inibir a liberação de ocitocina através da secreção de adrenalina, o que 
retarda ou mesmo interrompe o trabalho de parto (Uvnäs-Moberg, 2003). A cascata-do-medo está relacionada ao comportamento básico da espécie de lutar ou fugir, o qual se tenta evitar por ocasião do parto. O outro estado comportamental, e que é estimulado, é o de acalmar e conectar. Várias vantagens fisiológicas são identificadas quando o ambiente permite que a mulher esteja tranquila e conectada com a experiência, dentre elas estão: batimentos cardíacos e pressão arterial rebaixados, circulação e sensibilidade aumentadas, maior tolerância à dor das contrações, maior liberação de ocitocina etc. (Foureur, 2008).

Estudos recentes têm apontado que a ocitocina não está apenas relacionada ao trabalho de parto, parto e amamentação, mas também ao comportamento de vinculação mãe-bebê, dentre outros, como aponta Nephew (2012). Cada vez mais se encontram evidências de que a ocitocina é um hormônio envolvido nesta construção de apego materno-filial, induzindo um vínculo afetivo mais profundo, ao mesmo tempo em que está presente igualmente em outros eventos relevantes para a espécie, como a relação sexual. Com isso em vista, alerta-se para as consequências à espécie humana de nascimentos cirúrgicos em larga escala, os quais inibem a liberação fisiológica da ocitocina, impedindo assim o coquetel de hormônios essenciais à vinculação afetiva primordial (Foureur, 2008; Odent, 2000, 2008).

\subsection{EiC, o ambiente e o exercício do poder}

Conforme visto anteriormente, a teoria do território de nascimento considera as características físicas do ambiente, especialmente quando relacionadas com o outro conceito-chave ligado ao terreno, qual seja, a ideia de jurisdição. Através desta, os agentes da parteria poderão fazer uso de um poder que esteja a serviço dos interesses da mulher, especificamente, em favor do poder integrativo, que reflete necessidades mais profundas ligadas ao si-mesmo interior. Assim, o poder integrativo permite suscitar a integração corpo-mente-espírito, tanto da parturiente quanto das demais pessoas presentes no território de nascimento. Já o poder desintegrativo encontra-se mais relacionado com o ego e seus mecanismos de defesa, utilizados no intuito de controlar a situação, e lidar com suas próprias incertezas. Usualmente, os EiC emergem durante o parto quando a mulher está sendo conduzida pelo si-mesmo interior (inner self). O Quadro 1 resume algumas características comportamentais observadas na mulher em relação à fonte de poder nela atuante. 


\begin{tabular}{|c|c|}
\hline Quando o ego está no comando, a mulher: & $\begin{array}{l}\text { Quando o si-mesmo interior está } \\
\text { conduzindo, a mulher: }\end{array}$ \\
\hline está alerta ou hiper-alerta. & está sonolentamente desarmada. \\
\hline está muito falante. & $\begin{array}{l}\text { está silenciosa ou ruidosa; não } \\
\text { tagarelando. }\end{array}$ \\
\hline está orientada no tempo e no espaço. & $\begin{array}{l}\text { está amplamente inconsciente de tempo e } \\
\text { espaço. }\end{array}$ \\
\hline $\begin{array}{l}\text { preocupa-se em como vai lidar com o } \\
\text { futuro. }\end{array}$ & lida com um momento de cada vez. \\
\hline julga a si mesma e aos outros. & não está em postura de julgamento. \\
\hline pensa sobre como os outros a percebem. & $\begin{array}{l}\text { está despreocupada sobre como os outros } \\
\text { a percebem. }\end{array}$ \\
\hline tenta ficar no controle. & $\begin{array}{l}\text { está rendida ao controle do seu corpo e do } \\
\text { ambiente. }\end{array}$ \\
\hline $\begin{array}{l}\text { pensa sobre as pessoas ou coisas fora de si } \\
\text { mesma. }\end{array}$ & $\begin{array}{l}\text { foca o interior e percebe os sentimentos } \\
\text { corporalmente sem julgá-los ou controlá- } \\
\text { los. }\end{array}$ \\
\hline $\begin{array}{l}\text { tenta ser racional e evitar a } \\
\text { emocionalidade. }\end{array}$ & $\begin{array}{l}\text { solta a racionalidade e abraça a } \\
\text { emocionalidade. }\end{array}$ \\
\hline sente-se poderosa ou sem poder algum. & sente que tem poder suficiente. \\
\hline $\begin{array}{l}\text { sente-se cansada ou preocupada em ficar } \\
\text { cansada. }\end{array}$ & sente que tem energia suficiente. \\
\hline $\begin{array}{l}\text { força para que as coisas aconteçam (ou } \\
\text { tenta fazê-lo). }\end{array}$ & $\begin{array}{l}\text { permite o trabalho de parto acontecer em } \\
\text { seu próprio ritmo e à sua própria maneira. }\end{array}$ \\
\hline $\begin{array}{l}\text { assume as posições e comportamentos que } \\
\text { são esperados. }\end{array}$ & $\begin{array}{l}\text { move-se e se expressa intuitivamente aos } \\
\text { sinais corporais. }\end{array}$ \\
\hline $\begin{array}{l}\text { experiência as contrações do parto como } \\
\text { dor e sofrimento. }\end{array}$ & $\begin{array}{l}\text { pode experienciar as contrações como } \\
\text { oscilações de energia ao invés de dor. }\end{array}$ \\
\hline $\begin{array}{l}\text { quer interromper ou parar a dor e/ou só } \\
\text { quer senti-la inteiramente. }\end{array}$ & $\begin{array}{l}\text { dá boas vindas a cada contração e } \\
\text { sensação como um passo mais próximo } \\
\text { para segurar seu bebê. }\end{array}$ \\
\hline reclama da experiência. & foca-se na experiência sem reclamar. \\
\hline se ela verbaliza, está buscando simpatia. & $\begin{array}{l}\text { se ela verbaliza, faz isso como forma } \\
\text { sincera de expressar sua experiência; ela } \\
\text { diz 'está doendo' ou 'ahh', como } \\
\text { mecanismo de liberação. }\end{array}$ \\
\hline
\end{tabular}

Quadro 1. Discernindo a fonte de poder durante o parto. (Fahy \& Hastie, 2008 [tradução livre]).

Ser conduzida pelo si-mesmo interior remete à chamada partolândia. Em sua etnografia, Carneiro (2015) retrata o conceito considerando-o um elemento de resgate do significado da experiência de parto, uma 
vez que na sociedade contemporânea houve um esvaziamento dessa experiência. Sintetizada na resenha de Nakano e Bonan (2016, p. 2):

Partolândia é a categoria nativa com a qual as mulheres falam positivamente de alterações de consciência, transes, êxtases e descontroles relacionados à experiência do "parir diferente", a "estados outros de existência, que aconteceram entre gritos, gemidos, suor, posturas e atitudes impensadas socialmente" ( $p$. 256). Para a maioria dos médicos, essas situações conotariam risco e instabilidade, porém para as mulheres "representaram positividade e fruição de seus desejos mais próprios de como parir".

Neste contexto, postula-se que o acesso ao si-mesmo interior, relacionado à partolândia, tende a ocorrer quando há um ambiente seguro e o necessário acolhimento, por parte dos assistentes da parteria. No modelo integral de Wilber, a partolândia pode ser vista como o conjunto de manifestações comportamentais (Quadrante SD) que denotariam a imersão em estados psíquicos mais profundos do humano. Porém, caberia perguntar que indícios exteriores poderiam sugerir a emergência deste estado particular de consciência? 0 Quadro 2 fornece algumas pistas, tendo em vista especialmente os cuidadores envolvidos na assistência ao parto, dentre os quais o(a) profissional de psicologia. 


\begin{tabular}{|c|c|c|}
\hline $\begin{array}{l}\text { Em estado comum } \\
\text { (ordinário), a } \\
\text { pessoa: }\end{array}$ & $\begin{array}{l}\text { Em estado suavemente } \\
\text { incomum, a pessoa: }\end{array}$ & $\begin{array}{l}\text { Em estado profundamente } \\
\text { incomum, a pessoa: }\end{array}$ \\
\hline Está alerta & Está em devaneio & $\begin{array}{l}\text { Tem dificuldade de funcionar de } \\
\text { forma ordinária }\end{array}$ \\
\hline Fala facilmente & É capaz de falar se necessário & Pode ter dificuldade para falar \\
\hline $\begin{array}{l}\text { Está em contato com } \\
\text { a realidade } \\
\text { consensual }\end{array}$ & $\begin{array}{l}\text { Não está pensando sobre a } \\
\text { realidade consensual, a menos } \\
\text { que seja solicitada }\end{array}$ & $\begin{array}{l}\text { É menos capaz de expressar as } \\
\text { experiências em palavras }\end{array}$ \\
\hline $\begin{array}{l}\text { Está de olhos } \\
\text { abertos }\end{array}$ & $\begin{array}{l}\text { Está normalmente de olhos } \\
\text { fechados }\end{array}$ & Está de olhos fechados \\
\hline $\begin{array}{l}\text { Apresenta perfeita } \\
\text { consciência de } \\
\text { tempo }\end{array}$ & Pode perder a noção de tempo & Distorce o tempo \\
\hline $\begin{array}{l}\text { Apresenta perfeita } \\
\text { consciência de si e } \\
\text { dos outros }\end{array}$ & $\begin{array}{l}\text { Pode ter a percepção de si } \\
\text { mesmo meio borrada }\end{array}$ & $\begin{array}{l}\text { Pode se experienciar em um } \\
\text { tempo diferente de sua biografia } \\
\text { ou no reino transpessoal }\end{array}$ \\
\hline \multirow{3}{*}{$\begin{array}{l}\text { Apresenta } \\
\text { consciência dos } \\
\text { arredores }\end{array}$} & $\begin{array}{l}\text { Pode perder a consciência dos } \\
\text { arredores }\end{array}$ & $\begin{array}{l}\text { Tem menos pontos de referência } \\
\text { para a realidade ordinária }\end{array}$ \\
\hline & $\begin{array}{l}\text { Pode rápida e relativamente } \\
\text { mudar o foco e chavear para a } \\
\text { consciência ordinária }\end{array}$ & $\begin{array}{l}\text { Tem acesso a niveis mais } \\
\text { profundos de cura }\end{array}$ \\
\hline & & Tem acesso a estados místicos \\
\hline
\end{tabular}

Quadro 2. Reconhecendo os Estados Incomuns de Consciência (EiC). (Taylor, 1994; Fahy \& Hastie, 2008 [tradução livre]).

Oferecer condições e ambiência adequadas ao processo natural e fisiológico do parto favorece a emergência dos $\mathrm{EiC}$, especialmente a partolândia. Neste sentido, Grof \& Grof (1989) consideraram que o parto é um momento bastante propício a isto. O estado que surge durante o trabalho de parto não raro traz poderosos insights, emoções, mudanças de perspectivas e de estilos de vida. Assim, esta característica de "emergência" (Grof, 2000), presente neste evento tão marcante para a mulher, poderia lhe representar efetivamente um desenvolvimento psicoespiritual, envolvendo grandes mudanças em crenças, emoções, percepções de vida e de relacionamento consigo, com os outros, com o mundo e com Deus (Taylor, 1994, 1995). Tal transformação envolve um maior senso de integralidade, de bemestar e, portanto, de exercício do poder pessoal, também conhecido como empoderamento.

\subsection{EiC e 0 empoderamento feminino enquanto desenvolvimento}

Considerável parcela de mulheres refere que 0 ano em que 
engravidaram e deram à luz é uma época de crescimento pessoal e profundas transformações em suas vidas. Isto parece ser particularmente verdadeiro quando há um respeito pelas suas escolhas, e the são ofertadas as melhores condições de assistência. Isto significa um ambiente com o mínimo de intrusões possível, permitindo emergir os estados favoráveis a o parir (Fahy \& Hastie, 2008). Mesmo quando a condição clínica não é adequada ao parto natural, ainda assim é possível oferecer uma assistência respeitosa e favorável ao desenvolvimento psicológico da mulher.

A ideia geral de desenvolvimento no modelo wilberiano segue uma lógica estruturalista de progressiva complexidade e organização dos conteúdos da consciência, e embora não se limite à unidirecionalidade do estruturalismo clássico, pressupõe a expansão da percepção de si, do mundo e do sentido de vida. Trata-se, portanto, de um desenvolvimento psicoespiritual, mesmo o autor considerando a existência de múltiplos fluxos de consciência neste contínuo desvelarse de potencialidades humanas (Wilber, 2006). Dessa forma, pode-se pensar tal mecanismo básico fazendo parte da experiência do ciclo gravídico-puerperal.

Utilizando a metáfora da alquimia medieval, Nogueira (2013b) vai falar das etapas pelas quais a mulher atravessa para conquistar a si mesma, durante o período gravídico-puerperal, fazendo cumprir um anseio mais profundo do si-mesmo interior, na acepção usada anteriormente. Segundo a autora, a mulher inicia o processo de desenvolvimento desta etapa durante uma crise, que se instala quando a visão que ela faz de si, do mundo e seu modo de funcionar quanto à concepção, gestação e parto, já não a satisfaz mais; eis a fase da nigredo, relacionada à sensação de confusão e desconforto. Após este verdadeiro processo de morte das antigas visões, a mulher estará adentrando a fase da albedo, que é a aurora após uma madrugada escura, uma centelha de luz que surge, dando fôlego e continuidade ao processo de transformação. Mediante esta recémsurgida abertura, é possível fazer uma faxina interior, removendo o que já não lhe serve mais. Na sequência, vem a fase da citrinitas, a realização de um trabalho propriamente dito, definida por Nogueira (2013b, p. 82) como “o estado no qual a substância está carregada de novas energias para enfrentar novas experiências". Evidente que durante a realização do novo projeto, há os empecilhos, os obstáculos, as pedras do caminho. Porém, quando a mulher encontra o seu centro, a conexão com o si-mesmo interior, mantém a força transformadora e continua até a próxima e derradeira etapa do processo: a rubedo. Como o nome sugere, atinge-se o rubor, o vermelho da força propulsora final que dá nascimento ao novo, na metáfora alquímica: a pedra filosofal. "A iluminação da consciência é o prêmio de quem completa a obra alquímica e com ela seu processo de individuação" (Nogueira, 2013b, p. 103). Exemplificando esta 
etapa final do processo de transformação, a autora retrata o período expulsivo de uma mulher em processo de parto e nascimento:

“Uma força descomunal surgiu de dentro de mim... Senti-me grande, enorme, maior do que aquela minúscula sala, maior do que o planeta, do tamanho do universo. Uma energia poderosa e indescritível preencheu o meu mundo todo [...]" (Nogueira, 2013b, p. 99).

Um termo que vem aparecendo na literatura, que também fala deste processo de transformação feminina é o chamado empoderamento. Para além de um sentido mais externo como 'dar poder a alguém', aqui se está referindo a uma experiência bem mais profunda e complexa do que aquela referente à atitude racional (Nogueira, 2013a). Trata-se de um evento segundo o qual alguém emerge das camadas mais profundas da psique, a partir do encontro com as sombras interiores. Para isso, a mulher precisaria lidar com suas figuras internas de autoridade, além de encarar a própria alienação do corpo e dos instintos. Finalmente, na visão arquetípica da autora, seria preciso ainda que esta mulher equilibrasse as dimensões masculina e feminina em si mesma.

Empoderamento é voltar-se para a mulher negra dentro de si, aquela que permaneceu nas sombras, escondida, renegada, desprezada [...] e que precisa ser despertada, reconhecida e convidada para a festa da vida. Ela traz em si o ritmo natural, o ciclo da vida-morte-regeneração... (Nogueira, 2013b, p. 38).

Esta acepção do empoderamento reflete-se em relatos de parto como o que segue:

Eu fui a protagonista do meu parto e posso afirmar que enquanto meu filho nascia, eu renascia! o parto me permitiu descobrir quem sou e que posso ir muito mais além se acreditar que sou capaz, e deixar o Divino agir. Hoje eu entendo o que é tocar o Sagrado [Aline] (Núcleo Origem, 2015).

Outra pesquisa sugere um crescimento pessoal nesta mesma direção.

Sentiram-se empoderadas e fortes com força instintiva de mulher [...] seus medos passaram a não ser nada, foram superados. Significaram que passar pela experiência do parto fez com que se sentissem fortes, com coragem e capazes de enfrentar qualquer coisa e $[\ldots]$ crescer como mulher $[\ldots]$ (Campos, 2017, p.69). 
Obviamente, para que o desenvolvimento seja efetivo e possa ser caracterizado enquanto tal, as mudanças observadas precisam ter um caráter mais permanente, o que é melhor constatado mediante o acompanhamento das mulheres ao longo do tempo. Mesmo assim, podem-se observar alguns trabalhos indicando como o ciclogravídico-puerperal, que permite a experiência do tornar-se mãe, apresenta um caráter transformador para a mulher (De Felice, 2007; Piccinini, Lopes, Gomes, \& De Nardi, 2008).

\section{Conclusão}

A fenomenologia dos EiC na experiência de mulheres parturientes envolve estados de modificação na percepção de espaço e tempo, emocionalidade e intuição aguçadas, vivência e expressões ligadas a processos instintuais, profundos insights psíquicos, revivescência de traumas, inclusive do próprio nascimento, visualização de luzes ou seres ou sons indescritíveis etc. O conjunto destes estados tem sido designado pelas próprias mulheres como partolândia, e apresenta uma relação direta com o território de nascimento. Quando nele a mulher se sente segura e tem resguardada sua privacidade, pode relaxar e permitir que nela opere níveis mais instintuais de seu corpomente-espírito, que vão assumir o processo parturitivo mediante a liberação dos hormônios necessários à evolução do processo de parto. Do contrário, em circunstâncias de insegurança e violação do espaço, ativa-se no organismo feminino o estado de alerta, que inibe 0 trabalho de parto para defender sua integridade, prolongando 0 processo e, não raro, gerando significativo sofrimento na mulher.

O modelo integral adotado permite colocar em mais ampla perspectiva o fenômeno partolândia, na medida em que o situa em quatro dimensões (quadrantes): comportamental, donde se examina os hormônios e se observam comportamentos; social, donde se vê os sistemas institucionais e modos de produção relativos à assistência ao parto (hospital vs. casas de parto); cultural, donde se apercebem os valores e concepções relativos ao modo de prestar a assistência (mais tecnocrático ou mais holístico), e a dimensão intencional, donde se é possível investigar a experiência das parturientes, e seus estados de consciência. Com esta base, é possível pensar uma assistência que leve em conta a multidimensionalidade humana.

Relatos de mulheres que foram atendidas em suas necessidades mais integrais (físicas, emocionais, espirituais) ao longo do ciclo gravídicopuerperal, sugerem que elas se apropriaram do seu processo de parto, exercendo ativamente o protagonismo neste evento de vida tão significativo. Tal experiência parece suscitar uma transformação, não apenas pelo ingresso no universo da maternidade, mas pela 
maneira como puderam vivenciar a transição do processo parturitivo, enquanto verdadeira jornada psíquica digna de uma epopeia.

A partir destas conclusões, observa-se que os profissionais que atuam junto às mulheres durante o ciclo gravídico-puerperal, incluindo o(a) profissional de psicologia, têm um papel muito relevante e uma oportunidade ímpar de contribuir com o desenvolvimento da mulher; e paralelamente, com o do bebê, face ao impacto que a experiência da mãe tem na formação do vínculo pós-parto. Por outro lado, a presente reflexão reforça a necessidade de mudanças no modelo assistencial hegemônico de assistência ao parto, tendo em vista a importância do respeito à fisiologia do nascimento, aos melhores resultados obstétricos e, especialmente, à importância de devolver às mulheres o protagonismo deste evento, tão significativo e transformador em suas vidas e tão essencial à própria humanização da espécie.

\section{Referências}

Barreto, M. R. N. (2007). A Ciência do Parto nos Manuais Portugueses de Obstetrícia. Revista Gênero, 7(2), 219-236. doi: https://doi.org/10.22409/rg.v7i2.152

Campos, L. B. (2017). Ser-aí-mulher-que-vivenciou-o-partodomiciliar-planejado: contribuições para a enfermagem (Dissertação de Mestrado). Universidade Federal de Juiz de Fora, Juiz de Fora.

Carneiro, R. (2013). Daquilo que os médicos quase não falam: transe e êxtase na cena de parto. Experiências e percepções dissidentes de saúde e de bem-estar na contemporaneidade. Ciência \& Saúde Coletiva, 18(8), 2369-2378.

Carneiro, R. (2015). Cenas de Parto e Políticas do Corpo. Rio de J aneiro: Editora Fiocruz.

Davis-Floyd, R. (2001). The technocratic, humanistic and holistic paradigms of childbirth. International Journal of Gynaecology Obstetrics., 75(supl. 1), S5-S23.

Davis-Floyd, R. (2009). Perspectivas antropológicas del parto y el nacimiento humano. Buenos Aires: Editorial Creavida.

Debra-Pascali. (2009). Orgasmic Birth [DVD]. Documentário, USA.

De Felice, E. M. (2007). Transformação e "cura" através da experiência de ser mãe. Psyche, 11(21), 145-159. Retirado de http: // pepsic. bvsalud.org/scielo. php?script=sci_arttext\&pid=S1 415-11382007000200010\&lng =pt\&nrm=iso

Fahy, K., \& Hastie, C. (2008). Midwifery Guardianship: reclaiming the sacred in birth. In K. Fahy, M. Foureur, \& C. Hastie (Eds.), Birth Territory and Midwifery Guardianship: Theory for Practice, 
Education and Research (pp. 21-37). New York: Books for Midwives, Edinburgh.

Fahy, K., Parratt, J., Foureur, M., \& Hastie, C. (2011). Birth Territory: A Theory for Midwifery Practice. In R. Bryar, \& M. Sinclair (Eds.), Theory for Midwifery Practice (2nd ed., pp. 215-240). Basingstoke, UK: Palgrave.

Fourer, M. (2008). Creating birth space to enable undisturbed birth. In K. Fahy, M. Foureur, \& C. Hastie (Eds.), Birth Territory and Midwifery Guardianship: Theory for Practice, Education and Research (pp. 57-77). New York: Books for Midwives, Edinburgh. 178p.

Grof, S. (1985). Beyond The Brain: Birth, Death and Transcendence in Psychotherapy. Albany, N.Y.: State University of New York Press.

Grof, S. (1998). The Cosmic Game: Explorations of the Frontiers of Human Consciousness. Albany, N.Y: State University of New York Press.

Grof, S. (2000). Psicologia do Futuro. Rio de Janeiro: Heresis.

Grof, S., \& Grof, C. (1989). Spiritual Emergency: when personal transformation becomes a crisis. New York: St Martin's.

Gruzdev, N., \& Spivak, D. (2006). An exploratory investigation into the association of neuroticization, cognitive style, and spirituality to reported altered states of consciousness in women experiencing childbirth. International Journal of Transpersonal Studies, 25(1), 56-61.

Jung, C. G. (2000). Os arquétipos e o inconsciente coletivo. Petrópolis: Vozes.

Karadi, J. (2014). Childbirth as I nitiation Provided by Nature. Retirado de http://juliakaradi.com/wpcontent/ uploads/sites/19/2014/09/Childbirth-as-I nitiation1.pdf

Lahood, G. (2007, Summer). Transpersonal Events in Childbirth, Birth-giving Trauma and Ritual Healing. Inside Out, (52). Retirado de http://iahip.org/inside-out/issue-52-summer2007/transpersonal-events-in-childbirth-birth-giving-traumaand-ritual-healing

Nakano, A. R., \& Bonan, C. (2016). Cenas de parto e políticas do corpo. Cadernos de Saúde Pública, 32(11), 1-2. doi: https://dx.doi.org/10.1590/0102-311x00132716

Nephew, B. C. (2012). Behavioral Roles of Oxytocin and Vasopressin. In T. Sumiyoshi (Ed.), Neuroendocrinology and Behavior (pp. 49-82). London: InTechOpen. doi: 10.5772/50422.

Neumann, E. (1999). A Grande Mãe: um estudo fenomenológico da constituição feminina do inconsciente. São Paulo: Cultrix.

Nogueira, A. T. (2013a). A Alma do Parto. São Paulo: Biblioteca 24horas. 
Nogueira, A. T. (2013b). Parto Alquímico. São Paulo: Biblioteca 24horas.

Núcleo Origem: gestação, parto e maternagem. (2015). Parto: um evento sagrado. Retirado de http://nucleoorigem.com/2015/03/18/ parto-um-eventosagrado

Odent, M. (2000). A Cientificação do Amor. São Paulo: Terceira Margem.

Odent, M. (2008). Birth territory: the besieged territory of the obstetrician. In K. Fahy, M. Foureur, C. Hastie (Eds), Birth Territory and Midwifery Guardianship: theory for practice, education and research. Edinburgh: Books for Midwives.

Organização Mundial da Saúde (1996). Maternidade segura. Assistência ao parto normal: um guia prático. Genebra (SUI): OMS.

Piccinini, C. A., Lopes, R. S., Gomes, A. G., \& De Nardi, T. (2008). Gestação e a constituição da maternidade. Psicologia em Estudo, 13(1), 63-72.

Radloff, B. W. (2013). An Integral Approach to Pregnancy \& Childbirth.

Retirado

http:// www. integralpregnancy.com/integral-model-of-pregnancychildbirth/

Schwengber, D. D., \& Piccinini, C. A. (2004). Depressão materna e interação mãe-bebê no final do primeiro ano de vida. Psicologia, Teoria e Pesquisa, 20(3), 233-240.

Souza, K. J. (2014). Violência institucional na atenção obstétrica: proposta de modelo preditivo para depressão pós-parto (Dissertação de Mestrado). Programa de Pós-Graduação em Saúde Coletiva da Universidade de Brasília, Distrito Federal.

Spivak, L. I., Bechtereva, N. P., Spivak, D. L., Danko, S. G., \& Wistrand K. R. (1998). Gender specific altered states of consciousness. International Journal of Transpersonal Studies, 17(2), 181-185.

Taylor, K. (1994). The breathwork experience: exploration and healing in nonordinary states of consciousness. Hanford Mead, Santa Cruz.

Taylor, K. (1995). The ethics of caring: honouring the web of life. Hanford Mead, California.

Uvnäs-Moberg, K. (2003). The oxytocin fator. Tapping the hormone of calm, love, and healing. Cambridge, MA: Da Capo Press.

Wilber, K. (2000). Uma teoria de Tudo. São Paulo: Cultrix.

Wilber, K. (2006). Espiritualidade Integral: uma nova função para a religião neste início de milênio. São Paulo: Aleph.

Wilber, K. (2011). Psicologia Integral: consciência, espírito, psicologia, terapia. São Paulo: Cultrix. 
Woolger, J. B., \& Woolger, R. J. (2000). A deusa interior: um guia sobre os eternos mitos femininos que moldam as nossas vidas. São Paulo: Cultrix.

\section{Endereço para correspondência \\ Leonardo Xavier de Lima e Silva \\ Ministério Público de Pernambuco}

Gerência de Saúde e Assistência Social

Rua do Sol, 143, Ed. IPSEP, 6ㅇ andar, Santo Antônio, CEP 50010-470, Recife - PE, Brasil

Endereço eletrônico: leopsixavier@gmail.com

\section{Aurino Lima Ferreira}

Universidade Federal de Pernambuco

Centro de Educação

Rua Acadêmico Hélio Ramos, Cidade Universitária, CEP 50670-901, Recife - PE, Brasil

Endereço eletrônico: aurinolima@gmail.com

\section{Luiziane Souza Vasconcelos de Lima}

Prefeitura da Cidade do Recife

Maternidade Professor Arnaldo Marques

Avenida Dois Rios, s/n, Ibura, CEP 51230-000, Recife - PE, Brasil

Endereço eletrônico: luiziane.lima@gmail.com

Recebido em: 16/03/2016

Reformulado em: 24/12/2017

Aceito em: 29/01/2018

\section{Notas}

* Analista do Ministério Público do Estado de Pernambuco, Recife, Pernambuco, Brasil. Mestre em Psicologia Cognitiva (UFPE) e Doutor em Educação (UFPE). Apoio financeiro: CAPES - bolsa de doutorado do primeiro autor.

** Doutor em Educação pela UFPE e Professor do Programa de Pós-Graduação em Educação e do Departamento de Psicologia e Orientação Educacionais da UFPE.

*** Enfermeira obstetra da Prefeitura da Cidade do Recife, Recife, Pernambuco, Brasil. Mestra em Saúde da Criança e do Adolescente (UFPE).

Este artigo de revista Estudos e Pesquisas em Psicologia é licenciado sob uma Licença Creative Commons Atribuição-Não Comercial 3.0 Não Adaptada. 